\title{
Sosialisasi dan Peningkatan Keterampilan dalam Pemanfaatan Bahan Pengawet Alami pada Produk Nugget di Desa Ngringo, Kecamatan Jaten, Kabupaten Karanganyar
}

\author{
Winny Swastike $^{1 *}$, Edi Suryanto ${ }^{2}$ Jamhari $^{2}$ dan Rio Olympias Sujarwanto ${ }^{2}$ \\ ${ }^{1}$ Program Studi Peternakan, Fakultas Pertanian, Universitas Sebelas Maret, Surakarta, Indonesia; ${ }^{2}$ Program Studi \\ Ilmu dan Industri Peternakan, Fakultas Perternakan, Universitas Gadjah mada, Yogyakarta, Indonesia
}

Diterima: 31 Maret 2020; Disetujui: 26 April 2020

\begin{abstract}
Abstrak
Penggunaan pengawet sintetik sering digunakan dalam pengolahan bahan pangan, juga sering dijumpai dalam tabel kemasan. Penggunaan seperti formalin dan boraks juga masih digunakan pada beberapa jenis makanan. Sosialisasi dan peningkatan keterampilan dalam pemanfaatan bahan pengawet alami pada produk olahan pangan di Desa Ngringo, Kecamatan Jaten, Kabupaten Karanganyar bertujuan untuk meningkatkan pengetahuan dan keterampilan terutama dalam penggunaan pengawet alami dalam pengolahan pangan. Peserta kegiatan ini diikuti oleh kader PKK. Kegiatan ini terdiri dari 3 tahapan yaitu sosialisasi mengenai bahan pengawet, jenis pengawet dan bahayanya, kegiatan kedua merupakan kegiatan peningkatan pengetahuan berbagai jenis bahan pengawet alami di sekitar kita yang dapat digunakan dalam pengolahan pangan, dan kegiatan ketiga diakhiri dengan kegiatan mengaplikasikan bahan pengawet alami ke dalam olahan bahan pangan. Keberhasilan kegiatan ini dilihat dari persentase peningkatan indikator yang digunakan sebagai parameter dalam penentuan keberhasilan. Kesimpulan yang didapat dari kegiatan ini adalah kegiatan ini dapat meningkatkan pengetahuan mengenai pengawet sebesar $65 \%$, peningkatan peranan perempuan tentang bahan pengawet sebesar $60 \%$, peningkatan pengetahuan tentang diversifikasi produk sebesar $80 \%$ dan peningkatan pengetahuan tentang penggunaan bahan pengawet alami pada nugget sebesar $70 \%$.
\end{abstract}

Kata kunci: nugget dan pengawet alami; peningkatan ketrampilan; sosialisasi

\section{Dissemination and Enhancement of Skills in Utilizing Natural Preservatives in Processed Food Products in Ngringo Village Jaten District, Karanganyar Regency}

\begin{abstract}
The synthetic preservatives are often used in processing food and often found in the packaginginformation tables. Enhancing of dangerous preservatives such as formaldehyde and borax are also still found in food. Enchancing knowledge about the types of preservatives, the dosage and the dangers that can happen need to be done. This activity aims to improve knowledge and skills, especially in the utilization of natural preservatives in food processing. Participants in this activity were PKK cadres. This activity consists of 3 stages. The first stage was the socialization of preservatives, types of preservatives and the danger of using synthetic preservatives. The second activity was increasing knowledge of various types of natural preservatives around us that can be used in food processing. The third stage was the application of natural preservatives into the processed of chicken nugget. The success of this activity was seen from the increasing of indicators percentage that were used as
\end{abstract}

* Corresponding author: winny@staff.uns.ac.id

Cite this as: Swastike, W., Suryanto, E., Jamhari, \& Sujarwanto, R. O. (2020). Sosialisasi dan Peningkatan Keterampilan dalam Pemanfaatan Bahan Pengawet Alami pada Produk Nugget di Desa Ngringo, Kecamatan Jaten, Kabupaten Karanganyar. AgriHealth: Journal of Agri-food, Nutrition and Public Health, 1(1), 30-38. doi: http://dx.doi.org/10.20961/agrihealth.v1i1.40935 
parameters to determine the result. The conclusion obtained from this activity is that this activity can increase knowledge about the usage of natural preservatives in processed foods, especially nuggets, to replace synthetic preservatives.

Keywords: dissemination; enhancement skills; nugget and preservatives

\section{PENDAHULUAN}

Berdasarkan data profil Kabupaten Karanganyar tahun 2017, Kecamatan Jaten merupakan salah satu dari 17 kecamatan yang ada di Kabupaten Karanganyar. Luasan wilayah Kelurahan Ngringo adalah 420.266 ha (Kabupaten Karanganyar, 2017). Berdasarkan monografi batas wilayah Desa Ngringo bagian utara dibatasi oleh Desa Sroyo, wilayah sebelah timur dibatasi oleh Kabupaten Sragen, wilayah selatan dibatasi oleh Kabupaten Sukoharjo dan wilayah barat dibatasi oleh Kodya Surakarta. Jumlah penduduk Desa Ngringo sebanyak 28.100 jiwa dengan jenis kelamin laki-laki sebanyak $40 \%$ sedangkan wanita sebanyak 60\%. Desa Ngringo termasuk dalam katagori desa swasembada. Berdasarkan Permendagri Nomor 1 Tahun 2013 Pasal 1 bahwa Tim penggerak Pemberdayaan Kesejahteraan Keluarga (PKK) merupakan ujung tombak dalam kegiatan sosialisasi dan kegiatan meningkatkan keterampilan masyarakat. Mekanisme dan jaringan kerja PKK dari Tim Penggerak PKK terbentuk karena gerakan PKK adalah bagian yang tak terpisahkan dari pembangunan masyarakat, karena itu PKK menggunakan mekanisme penyelenggaraan pembangunan masyarakat yang dimulai dari keluarga.

Permasalahan yang sering dijumpai dalam kegiatan sehari-hari di level keluarga hingga masyarakat pada umumnya adalah penggunaan produk olahan yang sering dijadikan alternatif dalam penyediaan lauk. Pemilihan makanan olahan sebagai lauk dalam bentuk nugget, sosis, bakso dijadikan pilihan karena kepraktisan dalam penyajian, akan tetapi penggunaan pengawet sintetik sebagai Bahan Tambahan Pangan (BTP) seringkali tidak mengikuti Peraturan Badan Pengawas Obat dan Makanan Nomor 11 Tahun 2019 Tentang Bahan Tambahan Pangan. Minimnya Sosialisasi mengenai Peraturan Kepala Badan Pengawas Obat dan Makanan Nomor 36 Tahun 2013 tentang Batas Maksimum Penggunaan Bahan Tambahan Pangan Pengawet membuat produsen juga konsumen awam terhadap hal tersebut.
Dampak negatif yang ditimbulkan dari penggunaan BTP pengawet bersifat akumulatif di dalam tubuh. Dampak yang muncul dari level ringan hingga berat, dampak yang terjadi berupa iritasi kulit, mual, muntah, pusing, keracunan hingga kematian. Pemberian sodium benzoat secara in vivo pada hewan coba tikus pada dosis 60 dan $120 \mathrm{mg} \mathrm{kg}^{-1}$ dapat mengakibatkan penurunan haemoglobin $(\mathrm{Hb})$ secara nyata (Ibekwe et al., 2007). Penggunaan asam borat atau boraks dapat menyebabkan keracunan dengan tanda batuk, iritasi mata dan mulut, dan muntah (Kumar dan Srivastava, 2011). Peraturan Menteri Kesehatan RI Nomor 1168/MenKes/Per/X/1999 disebutkan ada 10 bahan yang dinyatakan sebagai bahan berbahaya dan dilarang penggunaannya dalam makanan. Bahan-bahan tersebut adalah asam borat dan senyawa-senyawanya serta formalin. Boraks merupakan contoh bahan toksik yang dapat menyebabkan gangguan kesehatan. Formalin pada umumnya digunakan dalam industri plastik, kertas, tekstil, cat dan mebel, juga digunakan untuk mengawetkan mayat dan mengontrol parasit pada ikan. Formalin diketahui dapat menyebabkan kanker. Pemberian formalin pada hewan coba tikus dapat mengakibatkan neuropathic pain. Oleh karena itu, penggunaan formalin sebagai pengawet makanan sangat dilarang (Benson et al., 2008),

Upaya yang dapat dilakukan untuk meminimalisir penggunaan BTP sintetik maupun pencegahan dalam penggunaan BTP yang dilarang dapat dilakukan dengan kegiatan sosialisasi dan meningkatkan pengetahuan mengenai BTP pengawet juga meningkatkan keterampilan dalam mencari alternatif pengganti BTP pengawet. Sosialisasi mengisyaratkan suatu makna dimana setiap individu berupaya menyelaraskan hidupnya ditengah-tengah masyarakat (Narwoko dan Suryanto, 2007). Lebih lanjut dijelaskan bahwa seseorang akan mengenal dan melakukan penyesuaian dengan keadaan tempat dia bersosialisasi. Lewat proses sosialisasi, individu-individu masyarakat belajar mengetahui dan memahami tingkah laku pekerti apakah yang 
harus dilakukan, dan tingkah laku pekerti apakah yang harus tidak dilakukan.

Selain sosialisasi juga perlu dilakukan peningkatan pengetahuan kelompok PKK sebagai perwakilan masyarakat yang menjadi target. Peningkatan pengetahuan ditujukan agar makin paham setelah dilakukannya sosialisasi sehingga mampu mengaplikasikan dan mengadopsi pengetahuan yang telah didapatkan. Pengetahuan adalah hasil penginderaan manusia, atau hasil tahu seseorang terhadap objek melalui indera yang dimilikinya. Intensitas perhatian dan persepsi terhadap objek yang didukung oleh panca indera dapat memengaruhi tingkatan pengetahuan. Sebagian besar pengetahuan seseorang diperoleh melalui indera penglihatan dan pendengaran (Notoatmodjo, 2010).

Berdasarkan hasil beberapa penelitian, di Indonesia banyak terdapat bahan alami yang mengandung komponen bioaktif yang memiliki fungsi sebagai pengawet maupun yang memiliki fungsi sebagai sumber antioksidan. Bahan pengawet alami berupa rempah-rempah mengandung zat antimikroba yang khas sehingga dapat digunakan untuk mengawetkan suatu bahan makanan antara lain minyak atsiri dalam tanaman sereh (Cymbopogon ciratus), ekstrak kunyit (Cucurma domestika) dan lengkuas (Alpinia galanga) untuk menghambat pertumbuhan bakteri, sehingga dapat digunakan sebagai bahan pengawet alami pada makanan (Winarno dan Rahayu, 1994). Buah peach, sweetcherry, mangga dan pisang (Zheng et al., 2007a,b; Valero et al., 2011; Huang et al., 2013; Jin et al., 2014) maupun sayur seperti wortel (Bhosale et al., 2011), bayam merah (Cefola dan Pace, 2015).

Kegiatan ini diharapkan agar dapat menjadi solusi untuk meningkatkan pengetahuan dan keterampilan melalui sosialisasi khususnya kader PKK di Desa Ngringo Kelurahan Ngringo, Kecamatan Jaten, Karanganyar. Manfaat yang diperoleh dengan berlangsungnya kegiatan ini adalah meningkatnya pemahaman baik individu maupun kelompok dan juga diaplikasikannya pengetahuan yang didapatkan setelah kegiatan sosialisasi terlaksana.

\section{BAHAN DAN METODE}

Kegiatan Pengabdian ini dilaksanakan di Desa Ngringo, Kelurahan Ngringo, Kecamatan Jaten, Karanganyar. Responden dalam kegiatan ini yaitu kader PKK. Metode penentuan lokasi dan responden dipilih secara purposive sampling yang berarti sampel dipilih dan ditetapkan berdasarkan pertimbangan-pertimbangan tertentu yang sesuai dengan tujuan penelitian (Sugiyono, 2016).

Metode kegiatan ini dilengkapi dengan metode survei untuk mengumpulkan data primer dari responden dan data sekunder dari dinas terkait. Teknik pengumpulan data adalah wawancara, observasi, Focus Group Discussion (FGD), penyuluhan tentang dan pelatihan mengenai Sosialisasi dan Peningkatan Keterampilan dalam Pemanfaatan Bahan Pengawet Alami pada Produk Olahan Pangan.

Metode yang digunakan dalam tahapan ini dibagi menjadi beberapa bagian:

1. Metode yang digunakan untuk sosialisasi melalui FGD yang juga dilakukan rangkaian evaluasi berupa pre-test dan post-test.

2. Metode peningkatan pengetahuan melalui FDG juga pengenalan bahan pengawet sintetik dan pengawet alami yang dapat digunakan dalam pengolahan pangan.

3. Metode aplikasi dan implementasi teknologi pengolahan daging berbasis hasil penelitian.

4. Metode evaluasi keseluruhan yang dapat diwakili dari questioner.

Analisis data kegiatan ini adalah analisis deskriptif. Tahapan pelaksanaan kegiatan pengabdian yang digunakan dalam kegiatan ini adalah:

1. Sosialisasi mengenai jenis bahan pengawet sintetik, bahaya pengawet sintetik, juga sosialisasi mengenai bahan pengawet alami yang ada di sekitar kita.

2. Peningkatan keterampilan mengenai bahan pengawet sintetik/buatan dan pengawet alami pada produk olahan pangan. Peningkatan keterampilan tersebut melalui kegiatan penyuluhan dan Focus Group Discussion (FGD) dengan melibatkan anggota kelompok PKK dan Kader PKK RT 01/RW 23 Desa Ngringo.

3. Aplikasi penggunaan bahan pengawet alami pada pengolahan produk pangan. Penerapan teknologi produksi melalui kegiatan pelatihan pembuatan nugget menggunakan pengawet rempah dan sayur.

4. Pre-test dan post-test. Peningkatan pengetahuan peternak setelah mengikuti penyuluhan dan pelatihan diukur dengan cara pre-test dan post-test. 
5. Pelaksanaan kegiatan monitoring. Monitoring dilakukan untuk mengetahui kemajuan dalam kegiatan pelatihan.

\section{HASIL DAN PEMBAHASAN}

\section{Pelaksanaan kegiatan pelatihan dan penyuluhan}

Kegiatan dilakukan secara serial, yaitu Sosialisasi, peningkatan pengetahuan dan keterampilan dan ditutup dengan pertemuan yang berisikan kegiatan pelatihan pengenalan berbagai pengawet alami dan pelatihan pengaplikasian bahan pengawet alami pada produk olahan pangan, nugget. Kegiatan sosialisasi diharapkan dapat membawa perubahan. Berdasarkan dampak dari sosialisasi dapat menyebabkan seseorang akan mengenal dan melakukan penyesuaian dengan keadaan tempat dia bersosialisasi. Lewat proses sosialisasi, individu-individu masyarakat belajar mengetahui dan memahami tingkah laku pekerti apakah yang harus dilakukan, dan tingkah laku pekerti apakah yang harus tidak dilakukan. Sosialisasi mengisyaratkan suatu makna dimana setiap individu berupaya menyelaraskan hidupnya di tengah-tengah masyarakat (Narwoko dan Suryanto, 2007).

Kegiatan pertama adalah kegiatan sosialisasi terkait pemberian materi berupa pengetahuan pengawet sintetik, bahan pengawet sintetik dan beberapa hasil penelitian terkait penggunaan bahan alami sebagai pengawet alami, sedangkan kegiatan kedua adalah peningkatan pengetahuan terkait bahan-bahan alami yang berfungsi sebagai pengawet alami. Pengetahuan yang diberikan dibatasi pada bahan alami yang khusus digunakan dan dapat diaplikasikan pada pengolahan pangan. Kegiatan ketiga mempraktikkan materi yang telah didapat pada hari pertama dan kedua. Adapun produk yang dipilih untuk dikembangkan oleh kelompok di Desa Ngringo adalah produk olahan daging berupa nugget.

Kelompok peserta pelatihan dibagi menjadi 4 kelompok kecil, masing-masing terdiri dari 10 orang peserta. Masing-masing kelompok diberikan satu set bahan baku (daging ayam fillet, tepung terigu, tepung tapioka, tepung panir, telur dan mentega) dan juga peralatan penunjang kegiatan (panci, talenan, pisau, baskom, dan kompor).

Kegiatan yang dilakukan bertujuan untuk mensosialisasikan dan meningkatkan keterampilan mengenai pengawet baik sintetik maupun alami pada bahan pangan maka beberapa kegiatan yang dilaksanakan yaitu:

1. Mengadakan dialog melalui kegiatan program FGD. FGD akan dilaksanakan oleh Tim pelaksana kegiatan dan pihak-pihak lainnya yang terkait, antara pihak pemerintah kelurahan maupun kecamatan.

2. Mengadakan Sosialisasi dan peningkatan pengetahuan melalui penjelasan berbagai materi yang menambah pengetahuan anggota dan kader PKK RT 01/RW 23. Kegiatan ini diawali dengan pre-test dan post-test untuk mengetahui respon dan peningkatan pengetahuan mengenai pengawet sintetik dan pengawet alami.

3. Melakukan pelatihan pengolahan bahan pangan menggunakan bahan pengawet alami berupa bawang putih dan wortel.

\section{Karakteristik responden}

Karakteristik responden dapat berpengaruh pada kesuksesan sosialisasi. Hal tersebut disebabkan responden merupakan agen sosialisasi yang berperan utama dalam kegiatan sosialisasi. Karakteristik responden dapat dilihat pada Tabel 1. Data responden berdasarkan karakteristik jenis kelamin terdapat $5 \%$ berjenis kelamin laki-laki sedangkan $95 \%$ berjenis kelamin perempuan. Responden laki-laki yang menghadiri kegiatan tersebut adalah ketua RT dan ketua RW setempat yang tertarik pada kegiatan ini.

Karakteristik responden ditinjau dari segi usia, persentase terbesar pada rentang usia 41-50 sebesar $37,5 \%$ kemudian disusul responden dengan rentang usia 31-40 sebesar 30\%. Hal tersebut disebabkan pengurus dan anggota kader PKK adalah perempuan usia produktif. Hal tersebut ditujukan agar kader PKK masih memiliki optimisme untuk ikut berperan aktif dalam kegiatan pembangunan yang dimulai dari lingkup keluarga. Usia produktif juga memiliki rasa ingin tahu yang besar untuk meningkatkan pengetahuan serta keterampilan. Hal ini dilakukan dengan cara mengulang kembali pengetahuan yang diperoleh dalam memecahkan permasalahan yang dihadapi pada masa lalu (Notoatmodjo, 2010). Bertambahnya usia seseorang biasanya akan lebih dewasa intelektualnya (Nursalam dan Efendi, 2008).

Data responden untuk jenjang pendidikan didominasi oleh D3/S1 sebesar 75\%. Hal tersebut juga memudahkan dalam melaksanakan kegiatan sosialisasi dan dalam upaya meningkatkan 
keterampilan. Jenjang pendidikan ternyata juga berkontribusi terhadap respon positif terhadap kegiatan ini. Respon positif tersebut dapat dilihat dari banyaknya peserta yang hadir, meskipun kegiatan ini dibuat secara berseri. Tingginya pendidikan diharapkan tingkat pengetahuan seseorang bertambah sehingga memudahkan dalam menerima dan mengadopsi perilaku yang bertambah (Notoatmodjo, 2005).

Tabel 1. Karakteristik responden di Kelompok Kader PKK

\begin{tabular}{lcc}
\hline \multicolumn{1}{c}{ Karakteristik } & Jumlah responden (orang) & Persentase (\%) \\
\hline Jenis kelamin & 2 & \\
Laki-laki & 38 & 5,0 \\
Perempuan & & 95,0 \\
Usia (tahun) & 3 & \\
$20-30$ & 12 & 7,5 \\
$31-40$ & 15 & 30,0 \\
$41-50$ & 10 & 37,5 \\
$50-60$ & 0 & 25,0 \\
P0 & & 0 \\
Pendidikan & 0 & 0 \\
SD & 0 & 0 \\
SMP & 10 & 25,0 \\
SLTA & 30 & 75,0 \\
D3 / S1 & & \\
Pengetahuan tentang & 38 & 95,0 \\
Formalin & 38 & 95,0 \\
Boraks & 15 & 37,5 \\
Pengawet sintetik & 12 & 30,0 \\
Pengawet alami & 15 & 37,5 \\
Bahaya pengawet & & \\
\hline
\end{tabular}

Keberhasilan sosialisasi dan peningkatan keterampilan dapat dilihat pada karakteristik responden (Tabel 1) khususnya pada pengetahuan terkait bahan pengawet. Pengetahuan mengenai formalin dan boraks sebagai pengawet sintetik berbahaya sebesar 95\% membuat responden dalam kegiatan ini memiliki antusias dalam mengikuti kegiatan. Peningkatan pengetahuan melalui sosialisasi terkait pengawet sintetik, pengawet alami dan bahayanya yang disebabkan pengawet yang masih dibawah $50 \%$ juga membuat responden aktif bertanya saat kegiatan berlangsung. Hal tersebut membuktikan bahwa proses belajar seorang anggota masyarakat untuk mengenal, menghayati norma-norma serta nilainilai masyarakat sehingga terjadi pembentukan sikap merupakan proses sosialisasi.

\section{Indikator keberhasilan kegiatan}

Keberhasilan kegiatan yang dilakukan Tim dapat dilihat dari peningkatan sebelum dan setelah kegiatan berlangsung. Hal tersebut disebabkan karena indikator keberhasilan program dapat diketahui dari peningkatan respon peserta yang mengikuti kegiatan tersebut. Indikator keberhasilan dapat diukur dari jumlah warga yang mengikuti kegiatan, frekuensi kehadiran, tingkat kemudahan penyelenggaraan, peningkatan kapasitas peserta kegiatan, peningkatan respon dan kepedulian. (Mardikanto dan Poerwoko, 2012). Parameter keberhasilan kegiatan dapat dilihat pada Tabel 2, dari keseluruhan rangkaian kegiatan terjadi peningkatan beberapa poin peningkatan pengetahuan peserta setelah mengikuti rangkaian kegiatan sosialisasi.

Keberhasilan kegiatan ini diharapkan dapat membawa kemajuan baik secara langsung dan atau tidak langsung. Juga diharapkan membawa dampat positif bagi masyarakat sebagai pengguna, akademisi sebagai tim ahli dan pemerintah sebagai pemangku kebijakan. Bersinerginya ketiga belah pihak maka akan menumbuhkan jiwa kewirausahaan, membuka lapangan pekerjaan yang akhirnya roda perekonomian dapat berputar dan meningkatkan kesejahteraan masyarakat baik secara khusus dan umum. Hal tersebut mengacu pada konsep kegiatan dengan melibatkan 
masyarakat harus menekankan pada dampak pengembangan baik dalam aspek sumberdaya manusia dan penciptaan peluang usaha sehingga dapat secara tidak langsung berimbas pada ekonomi masyarakat (Awang, 2010).

Evaluasi atas capaian keberhasilan kegiatan ini dapat diketahui melalui beberapa indikator diantaranya: (a) Terdapat peningkatan pengetahuan mengenai bahan pengawet, (b) Terdapat peningkatan pengetahuan pengawet alami di sekitar kita, (c) Terdapat peningkatan kesadaran akan peranan perempuan dalam masyarakat mengenai produk olahan, diversifikasi produk olahan, (d) Meningkatnya peran serta perempuan dalam peningkatan kualitas hidup keluarga, (e) Meningkatnya peran dan partisipasi masyarakat dalam pengawasan produk makanan olahan, (f) Terciptanya produk olahan daging dan diversifikasi yang dihasilkan dalam skala rumah tangga (Tabel 2 dan Gambar 1).

Tabel 2. Parameter keberhasilan kegiatan

\begin{tabular}{|c|c|c|c|}
\hline \multirow{2}{*}{ No. } & \multirow{2}{*}{ Parameter kegiatan } & \multicolumn{2}{|c|}{ Indikator keberhasilan } \\
\hline & & Sebelum kegiatan & Setelah kegiatan \\
\hline 1. & Pengetahuan pengawet & Minim & Optimal \\
\hline 2. & Pengetahuan pengawet alami & Minim & Optimal \\
\hline 3. & $\begin{array}{l}\text { Kesadaran dan peranan perempuan pada } \\
\text { bahan pengawet sintetik dan alami }\end{array}$ & belum ada akses & $\begin{array}{l}\text { terbuka akses dan mengalami } \\
\text { peningkatan }\end{array}$ \\
\hline 4. & $\begin{array}{l}\text { pemenuhan gizi keluarga asal olahan } \\
\text { daging yang ASUH }\end{array}$ & beli produk jadi & $\begin{array}{l}\text { dapat membuat produk yang } \\
\text { berkualitas dan } \\
\text { diverdifikasinya }\end{array}$ \\
\hline 5. & $\begin{array}{l}\text { Pembuatan Olahan Daging dengan } \\
\text { bahan pengawet alami }\end{array}$ & belum bisa & $\begin{array}{l}\text { Berkembang sesuai infomasi } \\
\text { terbarukan hasil penelitian }\end{array}$ \\
\hline 6. & $\begin{array}{l}\text { Penggunaan Bahan Tambahan Pangan } \\
\text { pada produk olahan daging }\end{array}$ & $\begin{array}{l}\text { kurangnya } \\
\text { pengetahuan }\end{array}$ & $\begin{array}{l}\text { Pencampuran sesuai kaidah } \\
\text { peningkatan pengetahuan }\end{array}$ \\
\hline 7. & Diversifikasi Produk Olahan & Belum ada & $\begin{array}{l}\text { Terciptanya produk } \\
\text { diversifikasi dari produk } \\
\text { olahan baru }\end{array}$ \\
\hline
\end{tabular}

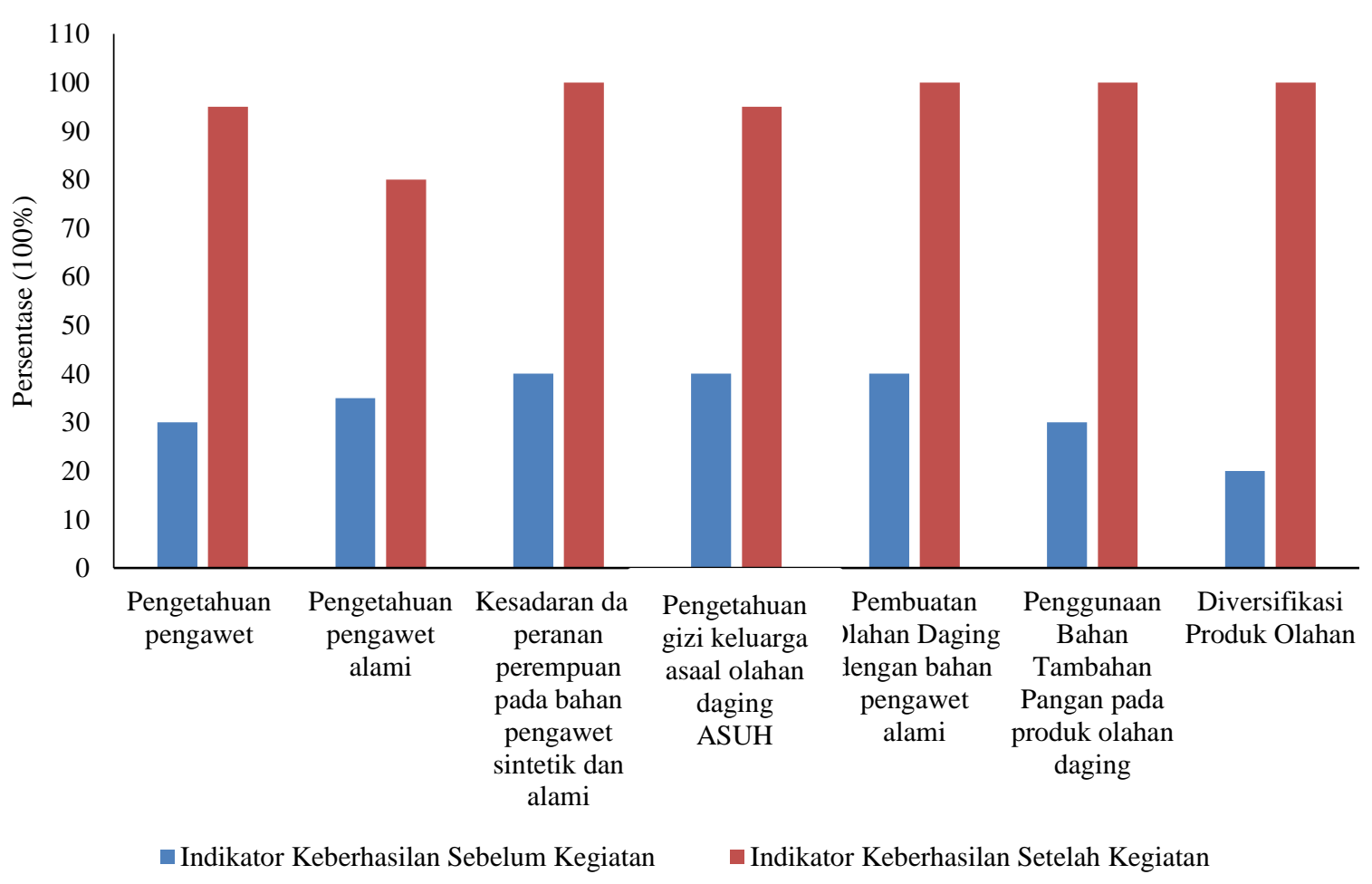

Gambar 1. Indikator capaian kegiatan pengabdian 
Tingkat ketercapaian indikator pada Gambar 1 merupakan pencerminan dari keberhasilan serangkaian kegiatan. Data tersebut didapatkan dari pengujian atas tingkat pemahaman awal (pretest) sebelum materi pelatihan diberikan dan pengujian akhir setelah dilakukan pelatihan (posttest) dengan berbagai macam parameter yang digunakan sebagai indikator keberhasilan kegiatan

Peningkatan dalam indikator pengetahuan pengawet sebesar $65 \%$ menunjukkan bahwa terdapat peningkatan dari yang sebelum kegiatan hanya sebesar 30\% kemudian menjadi 95\%. Parameter lain yang dapat dilihat lebih jelas pada Gambar 1 menunjukkan bahwa responden/peserta yang mengikuti kegiatan ini sangat antusias. Hal tersebut dapat dilihat dari peningkatan persentase pada sebelum dan sesudah kegiatan ini.

Peningkatan kesadaran peranan perempuan yang berada di dalam Kader PKK juga mengalami peningkatan sebesar $60 \%$. Hal tersebut disebabkan sebagai dampak dari sosialisasi yang mengarah pada perubahan kebiasaan dan keinginan berperan aktif dalam meengganti penggunaan bahan pengawet sintetik dengan bahan pengawet alami, terutama pada makanan olahan rumah.

Pengetahuan diversifikasi produk juga meningkat sebesar $80 \%$, hal tersebut dapat dilihat dari indikator capaian pada item tersebut (Gambar 1). Pelatihan baik berupa materi diversifikasi produk maupun proses pembuatan produk olahan nugget dengan berbagai macam bentuk dan variasi (Gambar 2). Antusiasme dan kesiapan untuk mengaplikasikan kegiatan ini merupakan indikator keberhasilan kegiatan. Keterlibatan peserta dalam beberapa rangkaian kegiatan juga menunjang keberhasilan (Gambar 3).

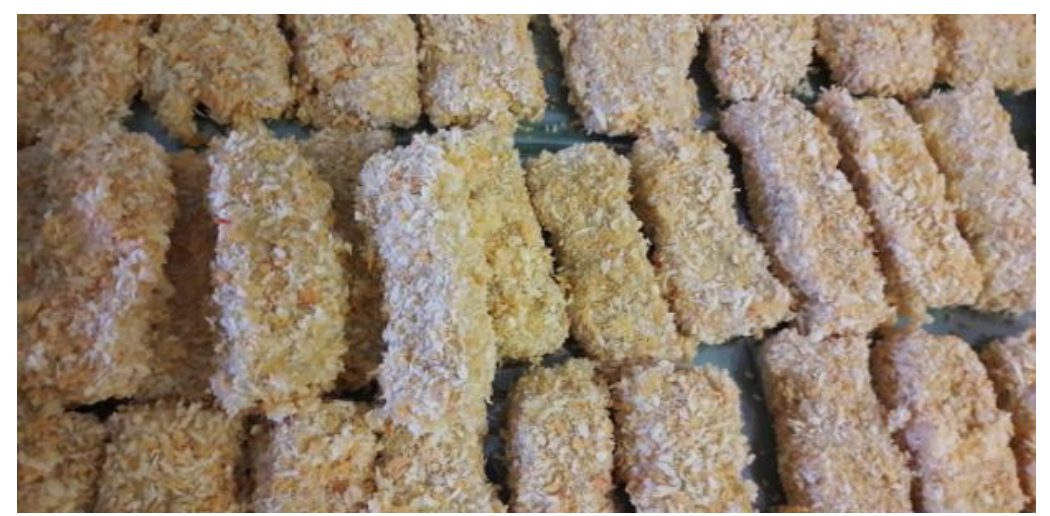

Gambar 2. Salah satu produk olahan nugget

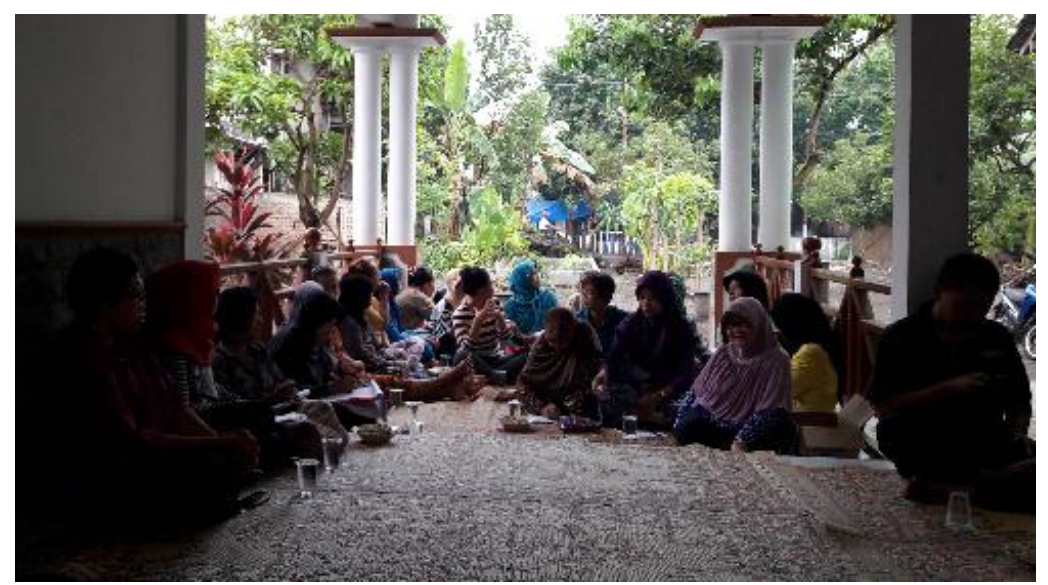

Gambar 3. Salah satu kegiatan sosialisasi

Kegiatan ini tidak hanya terhenti pada aplikasi masing-masing individu sebagai kader PKK, tetapi juga sebagai perempuan, juga ibu yang memegang peran penting dalam keluarga.
Keluarga yang sehat merupakan modal utama dalam mendukung kemajuan bangsa. Berawal dari keluarga sebagai satuan terkecil dari 
komunitas diharap dapat membawa perubahan ke lingkungan yang lebih besar lagi.

\section{KESIMPULAN}

Kegiatan yang telah dilaksanakan ini memberikan manfaat kepada kader PKK sebagai peserta khususnya maupun kepada masyarakat luas pada umumnya. Kegiatan ini dapat meningkatkan pengetahuan mengenai penggunaan bahan pengawet alami pada pangan olahan khususnya nugget untuk menggantikan penggunaan pengawet sintetik. Peningkatan pengetahuan mengenai pengawet sebesar $65 \%$, peningkatan peranan perempuan tentang bahan pengawet sebesar $60 \%$, peningkatan pengetahuan tentang diversifikasi produk sebesar $80 \%$ dan peningkatan pengetahuan tentang penggunaan bahan pengawet alami pada nugget sebesar 70\%. Kegiatan sosialisasi dan peningkatan ketrampilan dalam pemanfaatan alami pada produk nugget secara keseluruhan meningkat lebih dari $50 \%$.

\section{DAFTAR PUSTAKA}

Awang, A. (2010). Implementasi Pemberdayaan Pemerintahan Desa. Yogyakarta: Pustaka Pelajar. Halaman: 45. Tersedia dari https:// pustakapelajar.co.id/buku/implementasi-pem berdayaan-pemerintah-desa/

Benson, A. E. N., Martin, I., \& Corradin, L. (2008). The Rat Formalin Test Can It Predict Neuropathic Pain Treatment. Proceeding of Measureming Behavior. Netherland, 324-325 Agustus 2008. Tersedia dari https://measuring behavior.org/mb2008/individual_papers/Poste rs/PosterC21_Ellis.pdf

Bhosale, S. S., Biswas, A. K., Sahoo, J., Chatli, M. K., Sharma, D. K., \& Sikka, S. S. (2011). Quality evaluation of functional chicken nuggets incorporated with ground carrot and mashed sweet potato. Food Science and Technology International, 17(3), 0233-0237. https://doi.org/10.1177/1082013210382339

Cefola, M., \& Pace, B. (2015). Application of oxalic acid to preserve the overall quality of rocket and baby spinach leaves during storage. Journal of Food Processing and Preservation, 39(6), 2523-2532. https://doi.org/10.1111/jfp p. 12502

Huang, H., Jing, G., Guo, L., Zhang, D., Yang, B., Duan, X., \& Jiang, Y. (2013). Effect of oxalic acid on ripeningattributes of banana fruit during storage. Postharvest Biology and Technology, 84, 22-27. https://doi.org/10.10 16/j.postharvbio.2013.04.002

Ibekwe, S. E., Uwakwe, A. A., \& Monanu, M. O. (2007). Effect of oral intake of sodium benzoat on some haematological parameters of Wistar Albino Rats. Scientific Research and Essay, 2(1), 006-009. Tersedia dari http://www. academicjournals.org/app/webroot/article/arti cle1380705371_Ibekwe\%20et\%20al.pdf

Jin, P., Zhu, H., Wang, L., Shan, T., \& Zheng, Y. (2014). Oxalic acid alleviates chilling injury in peach fruit byregulating energy metabolism and fatty acid contents. Food Chemistry, 161, 87-93. https://doi.org/10.1016/j.foodchem.20 14.03.103

Kabupaten Karanganyar. (2017). Profil Kecamatan Jaten 2017. Tersedia dari http:// www.karanganyarkab.go.id/wp-content/uploa ds/2018/01/KECAMATAN-JATEN-DALAM -ANGKA-2017.pdf

Kumar, G., \& Srivastava, N. (2011). Genotoxic effects of two commonly used food additives of boric acid and sunset yellow in root meristems of trigonella feonum-groecum. Iran Journal Environmental Health Science Engineering, 4, 361-366.

Mardikanto, T., \& Poerwoko, S. (2012). Pemberdayaan Masyarakat dalam Perspektif Kebijakan Publik. Bandung: CV Alfabeta.

Narwoko, D. J., \& Suyanto, B. (2007). Sosiologi Teks Pengantar dan Terapan, Edisi Kedua, Cet. III. Jakarta: Prenada Media Group.

Nursalam, \& Efendi, F. (2008). Pendidikan Dalam Keperawatan. Surabaya: Salemba Medika.

Notoatmodjo, S. (2005). Metodologi Penelitian Kesehatan. Jakarta: Rineka Cipta.

Notoatmodjo, S. (2010). Promosi Kesehatan dan Ilmu Perilaku. Jakarta Rineka Cipta.

Peraturan Kepala Badan Pengawas Obat dan Makanan, [BPOM]. (2013). Peraturan Kepala Badan Pengawas Obat dan Makanan Republik Indonesia Nomor 36 Tahun 2013 Tentang Batas Maksimum Penggunaan Bahan Tambahan Pangan Pengawet. Badan Pengawas Obat dan Makanan Republik 
Indonesia. Tersedia dari https://jdih.pom.go. id/showpdf.php?u=KZaFgvQCDoKcuMbSX TQEKXIsK9gg62vHuMI4dVHHVU0\%3D

Peraturan Badan Pengawasan Obat dan Makanan, [BPOM]. (2019). Peraturan Badan Pengawasan Obat dan Makanan Nomor 11 Tahun 2019 Tentang Bahan Tambahan Pangan. Badan Pengawas Obat dan Makanan Republik Indonesia. Tersedia dari http:// standarpangan.pom.go.id/dokumen/peraturan/ 2019/PerBPOM_No_11_Tahun_2019_tentan g_BTP.pdf.

Peraturan Menteri Dalam Negeri, [Permendagri]. (2013). Peraturan Menteri Dalam Negeri Republik Indonesia Nomor 1 Tahun 2013 Tentang Pemberdayaan Masyarakat Melalui Gerakan Pemberdayaan dan Kesejahteraan Keluarga. Menteri Dalam Negeri Republik Indonesia. Tersedia dari https://kependudukan. jogjaprov.go.id/olah.php?module=hukum\&id =55_PERATURAN_MENTERI_DALAM_N EGERI_NOMOR_1_TAHUN_2013_TE NTANG_PEMBERDAYAAN_MASYARA KAT_MELALUI_GERAKAN_PEMBERD AYAAN_DAN_KESEJAHTERAAN_KELU ARGA.

Peraturan Menteri Kesehatan, [Permenkes]. (1999). Peraturan Menteri Kesehatan Republik Indonesia Nomor 1168/Menkes/ Per/X/1999 Tentang Perubahan Atas Peraturan Menteri Kesehatan Nomor 722/ Menkes/Per/IX/1988 Tentang Bahan
Tambahan Makanan. Menteri Kesehatan Republik Indonesia. Tersedia dari http:// hukum.unsrat.ac.id/men/menkes_1168_1999. pdf.

Sugiyono. (2016). Metode Penelitian Kuantitatif, Kualitatif dan $R \& D$. Bandung: Alfabeta.

Valero, D., Díaz-Mula, H. M., Zapata, P. J., Castillo, S., Guillén, F., Martínez-Romero, D., \& Serrano, M. (2011). Postharvest treatments with salicylic acid, acetylsalicylicacid or oxalic acid delayed ripening and enhanced bioactivecompounds and antioxidant capacity in sweet cherry. Journal of Agricultural and Food Chemistry, 59, 5483-5489. https://doi. org/10.1021/jf200873j

Winarno, F. G., \& Rahayu, T. S. (1994). Bahan Tambahan untuk Makanan dan Kontaminan. Jakarta: Pustaka Sinar Harapan.

Zheng, X., Tian, S., Meng, X., \& Li, B. (2007a). Physiologicaland biochemical responses in peach fruit to oxalic acidtreatment during storage at room temperature. Food Chemistry, 104, 156-162. https://doi.org/10.1016/j.food chem.2006.11.015

Zheng, X., Tian, S., Gidley, M. J., Yue, H., \& Li, B. (2007b). Effects of exogenous oxalic acid on ripening and decayincidence in mango fruit during storage at room temperature. Postharvest Biology and Technology, 45(2), 281-284. https://doi.org/10.1016/j.postharvbi o.2007.01.016 